Susanne Kjarbeck*

\title{
Den etnometodologiske konversationsanalyse som kulturanalytisk metode
}

\begin{abstract}
This article will focus on the ethnomethodological conversation analysis (CA) as a method for analysing cultural phenomena in conversation. It will present some of CA's basic assumptions about the social character of situated interaction and the use of context in conversation as well as discuss some recent research projects which, based on the conversation analytical approach, focus on cultural aspects of face-to-face or telephone conversation. Finally, it presents basic methodological aspects of the main traditions within cultural analysis, the functionalist paradigm and the interpretive anthropology, and relate the CA approach to these traditions. It is suggested that CA may make significant contributions to the ongoing discussion of methodology within the fields of cultural analysis and intercultural communication, be it the technical skills for analysing organization or identity in talk in interaction, the approach to context, to the interactive character of communication, or the reflexive understanding of the relationship between social and cultural norms and situated interaction.
\end{abstract}

\section{Indledning}

Denne artikel er forfattet på bagggrund af min Ph.d.-afhandling (Kjærbeck 1996a) om turn-taking og struktur i diskursenheder (lange argumenterende indlæg) i danske og mexicanske forhandlinger, hvor jeg anvender den etnometodologiske conversation analysis (CA) som metode. Med udgangspunkt i afhandlingens metode og resultater vedrørende diskursorganisation i forskellige kulturelle kontekster vil jeg i det følgende se nærmere på, hvordan den etnometodologiske konversationsanalyse kan bidrage i kulturanalytiske projekter inden for fagområdet interkulturel kommunikation. Formålet er således ikke at vise, hvordan man analysererer organisation i samtaler, hvilket normalt er fokus i konversationsanalytiske artikler, men derimod at redegøre for den etno-

\footnotetext{
* Susanne Kjarbeck

Handelshфjskolen i København

Institut for Interkulturel Kommunikation og Ledelse

Dalgas Have 15

DK - 2000 Frederiksberg
}

Hermes, Journal of Linguistics no. 20 - 1998 
metodologiske konversationsanalyses grundlæggende antagelser og metodologiske forhold, og belyse hvad metoden kan bidrage med inden for kulturanalysen.

Inden for forskningsfeltet interkulturel kommunikation har problemstillingen om hvordan kulturelle træk viser sig sprogligt været på dagsordenen siden 50'erne (Dahl 1995). Det var den amerikanske antropolog E.T. Hall der i 1959 gav startskuddet til den nye disciplin med bogen The Silent Language, hvor han bl.a. konkluderede "culture is communication and communication is culture". Inden for interkulturel kommunikation har disse betragtninger udgjort et fundament, og interessen har i høj grad samlet sig om at analysere de underforståede regler for kommunikativ adfærd, der ifølge denne tankegang gælder i forskellige nationalkulturelle kontekster.

Fagområdet interkulturel kommunikation har været præget af ønsket om at anvende den funktionalistiske kulturanalyses makrokategorier som fx. individualisme, kollektivisme og forskellige former for tidsopfattelse på kommunikation (se fx. artiklerne i Samovar \& Porter 1991). Navnlig de universelle dimensioner til kulturanalyse, som findes i findes i Halls og Hofstedes arbejder (se Hall \& Hall 1990, og Hofstede 1980, 1991) har været anvendt. Det har medført to vigtige forhold: For det første at man har delt kulturforståelse med ophavsmændene til disse dimensioner. Man har i høj grad baseret sig på de kulturanalytiske antagelser, der ligger til grund for Halls og Hofstedes teorier; fx. deles den grundlæggende antagelse, at kultur determinerer adfærd. For det andet har det medført, at man har arbejdet deduktivt. Man har i overvejende grad taget udgangspunkt i kulturanalytiske kategorier og søgt at applicere disse på sproglige forhold. Det er endvidere karakteristisk, at mange forskere inden for interkulturel kommunikation ikke har unders $\emptyset \mathrm{gt}$ et konkret sprogligt materiale, men har baseret den sproglige del på egne eller andres antagelser om, hvordan sproget fungerer.

Et særligt metodologisk problem inden for interkulturel kommunikation har været den usystematiske anvendelse af analytikerens personlige mere eller mindre eksotiske erfaringsverden. Den amerikanske antropolog Michael Moerman siger i sin artikel fra 1996 (oversættelse, SK): "den generelle metode - hvis man da kan kalde det en metode - er at sammenligne idealiserede versioner af én kultur med anekdoter om en anden"; han refererer her til Nomura \& Barnlund (1983), Lebra (1976), Doi (1973) og Condon (1984). Analytikerens erfaringer har i 
interkulturel kommunikation været anvendt på en usystematisk måde i modsætning til i antropologien, hvor etnografens indlevelse i den fremmede kultur udgør en metodisk komponent i kulturanalysen.

Forskere, der i disse år anvender den etnometodologiske mikroanalyse til projekter inden for interkulturel kommunikation (se fx. Day \& Firth 1996, Gramkow 1996, Kjærbeck 1996a og b, McIlvenny 1996, Rasmussen 1996 og under udgivelse, Steensig 1996) skal forstås på den baggrund. Der er opstået et stærkt $\emptyset$ nske om at blive bedre til at dokumentere sproglig organisation, for derigennem at kunne begrænse den personlige interpretation. Bidragene til analyse af relationen kommunikation-kultur baseres i denne tradition på konkret samtalemateriale, som normalt optages på video. Man anvender en induktiv tilgang, tager udgangspunkt i empirien, og analyserer optagelser af samtaler og detaljerede trasskiptioner af samtalematerialet. Den kulturforståelse, der er knyttet til denne fremgangsmåde og til den etnometodologiske metode som sådan, er at kulturen konstrueres i interaktionssituationer, i hvilke deltagerne er orienteret mod bestemte sociale og kulturelle normer, men altså ikke nødvendigvis følger dem.

Denne artikel består af 3 dele. Jeg vil først gøre rede for den etnometodologiske konversationsanalyses grundlæggende antagelser, metodologiske forhold og dens forhold til kontekst. Dernæst vil jeg diskutere hvad metoden kan bidrage med inden for kulturanalysen. Endelig vil jeg belyse, hvordan den etnometodologiske konversationsanalyse placerer sig i forhold til andre kulturanalytiske metoder.

\section{Den etnometodologiske konversationsanalyses grund- laggende antagelser og metodologiske forhold}

CA har dybe metodologiske rødder i den sociologiske tradition etnometodologi, der opstod i USA i 1950'erne og slog igennem i 60'erne, og hvis mest fremtrædende grundlægger var Harold Garfinkel. Etnometodologiens navn refererer til folks eller medlemmers metoder til at organisere verden (Silverman 1993), metoder til at producere og interpretere sociale handlinger, herunder verbal interaktion. Man interesserer sig for de procedurer eller regler, som sociale individer er bekendt med og tager i anvendelse i det daglige liv for at få andres handlinger til at give mening og for at gøre egne handlinger forståelige for andre (Garfinkel \& Sacks 1970). Derfor er etnometodologernes hovedinteresse, 
hvordan social interaktion skabes, og ikke hvorfor. Mange konversationsanalytikere inddrager dog forklarende forhold på et senere tidspunkt $\mathrm{i}$ analysen, jvf. afsnit 3.

En grundlægggende antagelse inden for etnometodologien er for det første, at aktørerne er i besiddelse af en social kompetence i at skabe og forstå handlinger, og desuden at denne kompetence er i stadig udvikling. Disse betragtninger bygger på Garfinkels forståelse af refleksivitet, der betegner det gensidigt determinerende forhold mellem konkrete realiseringer i interaktionen og underliggende mønstre, forstået som normative strukturer for social adfærd som individet har kendskab til. Det der gør forholdet dynamisk er, at de konkrete realiseringer i interaktionen ikke udelukkende skabes på basis af de underliggende mønstre; de kan afvige og således revidere de underliggende mønstre. De underliggende mønstre kan projicere bestemte udviklinger i interaktionen, og således være med til at tilvejebringe forståelse.

For det andet er det en grundlæggende antagelse, at en social handling, som fx. en sproglig handling, ikke optræder isoleret, men indgår som en del af en række handlinger, der indbyrdes er afhængige og formmæssigt tilpasset hinanden. De allerede producerede handlinger kan signalere, hvad der efterfølgende bliver produceret, og den senest producerede del kan til gengæld føre til en ny forståelse af det forudgående. Betydningsdannelsen forstås som en proces i konstant udvikling.

Disse etnometodologiske antagelser deles af den konversationsanalytiske tradition, der sidst i 1960'erne skiller sig ud som en selvstændig aflægger af etnometodologien. I starten var det først og fremmest Harvey Sacks, der udviklede metoden. Sidenhen kom samarbejdet med de øvrige grundlæggere, Emanuel Schegloff og Gail Jefferson, i stand.

Konversationsanalysen er en udpræget empirisk analysetradition, og denne interesse for empirien bygger netop på den etnometodologiske antagelse om, at der sker en konstant opbygning af forståelse mellem parterne i en samtale. Da deltagerne viser hinanden, hvordan de har forstået interaktionen, kan analytikeren ligeledes gøre brug af disse markeringer, i et fors $\emptyset \mathrm{g}$ på at beskrive hvad der foregår. Man interesserer sig for at beskrive interaktionen fra deltagernes perspektiv. Den altoverskyggende interesse for empirien hænger endvidere sammen med den etnometodologiske grundantagelse, at virkeligheden først og fremmest 
konstrueres socialt, mellem deltagerne i interaktive situationer (Hilbert 1992).

Konversationsanalysen adskiller sig fra andre samtaleanalytiske metoder ved at fokusere på organisation af aktiviteter. Typisk interesserer en CA-analytiker sig for at vise forekomsten af samtaleorganisatoriske strukturer, som deltagerne "orienterer sig mod". Begrebet "at være orienteret mod" afspejler den etnometodologiske opfattelse af, at samtalens deltagere handler i forhold til normative strukturer, som kan identificeres $\mathrm{i}$ interaktionen, men som dog ikke determinerer dens udvikling. De konversationelle metoder, der tages i anvendelse i en konkret samtalesituation, er samtidig lokalt betingede.

CA er endvidere en sekventielt baseret metode, man analyserer sekvenser af taleture og andre mikrofænomener i den konversationelle kontekst, hvor de optræder. Enhver kommunikativ handling forstås som dobbelt kontekstuel, idet den både er skabt af den kontekst, den relaterer sig til det forudgående materiale, og den er selv kontekstskabende, idet den vil udgøre konteksten for den næste taletur i en sekvens.

Et interessant spørgsmål som jeg vil belyse i det følgende er, hvilke former for kontekst CA kan forholde sig til udover den sekventielle kontekst i samtalen, som er et analytisk udgangspunkt i denne tilgang.

Indledningsvis skal det nævnes, at hverken etnometodologien eller CA har haft en kulturproblemstilling som deres centrale fokus. Som det er fremgået, taler man om sociale handlinger osv. Toneangivende personer som Gail Jefferson repræsenterer den mindst kontekstorienterede fløj inden for CA. De etnografisk orienterede projekter, kulturkontrastive undersøgelser eller interkulturelle lingua franca-samtaler opfatter Jefferson som problematiske, fordi hun mener, at såvel analytikerens som samtaledeltagernes sproglige kompetence som "native speakers" er en forudsætning for at kunne hhv. udtrykke og beskrive den "forventede" sproglige organisation i samtalen. Dette synspunkt begrundes altså i forholdet til de normative strukturer, der ifølge etnometodologien er et væsentligt element i skabelsen og forståelsen af aktiviteter.

Det der kendetegner de kontekstorienterede projekter inden for CA er, at de tager udgangspunkt i empirien, samtaleanalysen foretages på mikroniveau uden anvendelse af forudsatte makrokategorier. Analytikeren er først og fremmest interesseret i, hvad der foregår i datamaterialet. Først når man har foretaget en formel analyse og ved, hvad der er belæg for i samtalerne, giver man sig til at generalisere resultaterne til 


\section{4}

makroniveau, fx. til samtaletyper der i deres struktur adskiller sig fra almindelige dagligdags samtaler så som læge-patient-samtaler, mødesamtaler, retsmøder osv.

Konversationsanalytikerne mener, at betegnelser som "lægekonsultation", "retsmøde" "undervisning" osv. kan være forstyrrende kategorier for analysen af materiale fra institutionelle samtaler. Man anvender ikke generelle etnografiske informationer, men undersøger i stedet for, hvordan samtalens deltagere i et større korpus viser en orientering mod en institutionel eller anden form for kontekst. Ofte er samtalerne bygget op efter særlige strukturer i de institutionelle samtaler, de antager interaktionsmønstre som muliggør eller er hensigtsmæssige for udførelsen af den formelle aktivitet. Der er tale om, at de konversationelle ressourcer, som man finder i almindelige dagligdags samtaler, tilpasses den institutionelle samtales sigte. Det kan fx. dreje sig om særlige systemer for tildeling af taleture, sådan som Atkinson \& Drew (1979) viser om interaktion i retssalen, en særlig sekvensstruktur der fx. er domineret af spørgsmål og svar, sådan som det ofte er tilfældet i læge-patient-samtaler, eller særlige taleformater som Silverman (1993) har vist i rådgivningssamtaler. Desuden fokuserer forskellige studier inden for CA på, hvordan den samlede institutionelle aktivitet er struktureret, hvilke subaktiviteter og faser den består af. Fokus er også i den sammenhæng på "members' methods", på hvordan deltagerne skaber forskellige typer aktivitet. De konversationsanalytiske redskaber synes særlig relevante for kulturanalysen, fordi man ved hjælp af dem kan analysere organisation af aktiviteter i forskellige kultursammenhænge.

Inden for CA er der gennem årene foregået en løbende diskussion af, hvad relevant kontekst er, og af hvordan man med CA-metoden kan analysere kontekst. Jeg skal her begrænse mig til at nævne Schegloffs holdning, før jeg går over til den antropologiske gren af CA. Schegloff (1987, 1991, 1992a, 1992b) markerer sig stærkt overfor de tolkende anvendelser af social og kulturel kontekst og mener, at analysen af deltagernes perspektiv også i denne sammenhæng kan anvendes som et relevanskriterium. Den relevante kontekst er den, der i den konkrete situation optræder som relevant for samtaleparterne, og derfor er at finde $\mathrm{i}$ materialet. Optræder fx. etniske identiteter som relevant kontekst, må de være påviseligt relevante for produktion og interpretation af adfærd $\mathrm{i}$ interaktionen (Schegloff 1992a). Denne holdning udgør et grundfæstet udgangspunkt for konversationsanalytikernes behandling af kontekst. 
Schegloff fører diskussionen videre ved at introducere begrebet "proceduremæssig konsekvens", idet han sætter spørgsmålstegn ved betydningen af den påviseligt relevante kontekst, hvis ikke den optræder som et systematisk forekommende træk i interaktionen, sådan som det er tilfældet med de ovennævnte organisatoriske mønstre i institutionelle samtaler.

\section{Hvad kan CA bidrage med i kulturanalysen?}

På den mest kontekstorienterede fløj af CA-traditionen har antropologerne Michael Moerman og Jack Bilmes dannet skole (se fx. Moerman 1988, Bilmes 1992 og 1994). De har anvendt konversationsanalyse til etnografiske unders $\emptyset$ gelser, og betragter konversation som et interessant datamateriale, der ikke er påvirket af observatørens tilstedeværelse på samme måde som fx. interviewmateriale er. Moerman og Bilmes mener, at man ved at analysere mikrofænomener i samtaler fra en bestemt kultur, fx. thai-samtaler, kan få et vidnesbyrd om social organisation i den pågældende kultur, og de betragter begge CA som en teknisk metode til kulturanalyse. På denne måde kombineres konversationsanalyse med etnografi; med konversationsanalysens stringens foretager de en formel beskrivelse af konkrete interaktioner, og med etnografiske informationer gør de sig selv og læseren i stand til at forstå, hvad interaktionen handler om. De etnografiske oplysninger inddrages, når de gøres relevante i samtalen, og når inddragelsen af dem er påkrævet for at forstå interaktionen. Det drejer sig typisk om den studerede gruppes erfaringsverden og livsvilkår. Moerman vedkender sig, at analytikeren godt kan gå glip af noget, der faktisk har betydning for interaktionen ved at begrænse sig til den kontekst, som deltagerne gør relevant i samtalen, men fordelen ved denne fremgangsmåde er, at man ikke kommer til at forklare samtalen med forkerte former for kontekstuelle kategorier (1988:15).

Denne antropologiske gren af CA fokuserer på en kulturproblemstilling. Den begynder at profilere sig som en kulturanalytisk metode, og går i dialog med andre antropologiske metoder. Det sker navnlig i Moerman (1988), hvor et særligt navn for etnografisk CA lanceres, nemlig Culturally Contexted Conversation Analysis (der forkortes CCCA). 
Moerman (1988) foretager en undersøgelse af de mikrosproglige fænomener turn-taking, reparatur (dvs. korrektion og søgen efter ord) og person-reference i samtaler på thai og sammenligner sine resultater med amerikansk engelsk. Han viser, at deltagerne i overvejende grad anvender de samme konversationelle ressourcer i de to kulturelle kontekster, men at der også er tale om visse forskelle i anvendelsen af turntaking-systemet, og dem forklarer han med aktørernes orientering mod bestemte sociale kategorier og mod en specifik kulturel kontekst.

Moermans (1988) mest centrale analyse af person-reference sker i kapitlet "Society in a grain of rice". Materialet består af et kort uddrag af en samtale mellem et antal landsbyboere, en udsendt thai embedsmand og antropologen. Samtalen handler overordnet om, hvordan landsbyboerne skal behandle antropologen, og embedsmandens opgave er at instruere bønderne. Gennem en sekventiel analyse viser Moerman, at embedsmanden introducerer en dikotomi, der går på dem der spiser klæbende ris, som man gør på landet, og dem der spiser normale ris, som man gør i byen. Han viser, hvordan kategoriseringen i disse to slags mennesker finder sted og udvikler sig i interaktionen, og hvordan de impliceredes identitet forhandles ud fra disse kategorier. Embedsmanden omgår den etnisk baserede distinktion af risspisere, som landsbyboerne har gjort gældende i samtalen, og anvender sin egen klassebaserede distinktion. Der foregår således ikke alene en forhandling om hvem, der tilhører hvilken kategori, men også om hvad kategorierne refererer til. Han viser den aktive, situationelle anvendelse af kulturelle ideer, viser hvordan det etnometodologiske begreb "doing being" realiseres i konstruktionen af konversationelle aktiviteter i samtalen. På grund af sin empirisk baserede tilgang begiver Moerman sig ikke ud i eksplicitte generaliseringer af sine resultater, men betragter dem blot som et indblik i kulturen på dens egne præmisser.

Moerman (1988) henvender sig såvel til den sociologisk orienterede fløj af konversationsanalytikerne som til antropologerne. Han ønsker at vise konversationsanalytikerne, at det kan være nødvendigt at kæde mikrofænomer sammen med forhold fra makroniveauet, når man har at gøre med materiale fra en hel anderledes social og kulturel virkelighed; Moerman viser, hvordan oplysningerne fra de konversationelle data konstant suppleres med information om forholdene $i$ Thailand og i den landsby, hvor undersøgelsen finder sted, for at give mening. Moerman viser samtidig antropologerne, at forhold som klasse, etnicitet og vær- 
dier ikke er forudsatte størrelser, der med generel gyldighed kan forklare social interaktion; de udtrykker derimod sociale og kulturelle forhold, som konstrueres i interaktionen; de kan enten opstå eller udvikles i interaktionen, eller blot gøres aktuelle, men under alle omstændigheder afhænger det af den enkelte interaktionssituation, om og hvordan disse kategorier behandles. Betydning konstrueres i situationen, og deltagernes anvendelse af betydningsbærende elementer fremgår af deres samtaler.

Mens Schegloff anerkender Moermans (1977) metode til analyse af reparatur i samtaler på thai, er den mere vidtgående CCCA fx. blevet kritiseret fra konversationsanalytisk hold af Mandelbaum (1990/91) og Pomerantz (1990/91), der mener at interaktionen tillægges udokumenterede ressourcer vedrørende kontekst. De betvivler relevansen af de kontekstuelle oplysninger og mener, at de kan være direkte fejlagtige. De mener, at Moerman tolker ud over, hvad der er belæg for i samtalerne og at det er den interne kontekst i interaktionen, der giver den sproglige aktivitet mening.

Mens de sociologisk orienterede konversationsanalytikere, der beskæftiger sig med data fra deres egen nationalkultur eller fra den vestlige kulturkreds, taler om "sociale" metoder til samtaleorganisation, mener de antropologisk orienterede konversationsanalytikere, som analyserer fremmede kulturer, at der er tale om såvel sociale som kulturelle praksisser. I deres analyser er det ikke muligt at holde det sociale og det kulturelle ude fra hinanden. I Moerman (1996) behandles det sociale og det kulturelle dog ikke helt så entydigt.

De kulturanalytiske projekter, der anvender den etnometodologiske konversationsanalyse som metode, fokuserer enten på konstruktion af identitet eller på organisatoriske aspekter af samtaler. Udover de her nævnte antropologer har Paul McIlvenny (1996) bidraget med en analyse af kulturel identitet. McIlvenny (1996) viser, hvordan deltagere fra forskellige nationalkulturer lokalt forhandler deres kulturelle identiteter ved at kommentere forskellige kulturelle karakteristika, fx. ved brug af mimik, latter og verbale ytringer. Når det gælder konstruktion af identiteter i interaktion, synes CA-terminologien "doing being" at være særlig anvendelig. Dette begreb giver udtryk for, at man i denne analysetradition opfatter identiteter som noget, deltagerne konstruerer i situationen, i modsætning til permanente konstitueringer af identiteter. 
Identiteter er i denne opfattelse noget, man går ud og ind af, og som man definerer sig i forhold til.

Af de kulturanalytiske projekter, der undersøger organisatoriske forhold vil jeg først nævne Rasmussens (1996, se også under udgivelse) og Gramkows (under udarbejdelse, se også 1996) Ph.d.-afhandlinger, hvor de undersøger lingua franca-samtaler. Rasmussen (1996) beskæftiger sig i sin afhandling med kulturelle specifika i forretningssamtaler og viser, hvordan danske og tyske normer for tiltaleadfærd i form af det danske "du" og det tyske "Sie" ikke udgør en kulturel barriere i kommunikationen mellem dansker og tysker. Tværtimod forhandler interaktørerne sig frem til de anvendte tiltaleformer og normaliserer eventuelle afvigelser. De tilpasser på en måde kommunikationen til hinanden og reagerer altså ikke negativt på afvigelser. Dette arbejde viser nogle ganske anderledes resultater end den hidtidige forskning inden for interkulturel kommunikation, som i høj grad opfatter kulturforskelle som barrierer.

Gramkows (1996) datamateriale består af telefonsamtaler, forretningssamtaler mellem et dansk firma og dets udenlandske forbindelser. Han viser, at taleoverlap, der opstår i de analyserede samtaler, ikke er problematiske. Taleoverlappene anvendes tværtimod som kooperative sproglige midler, der viser samtalepartneren opmærksomhed, bekræfter relationen mellem parterne, udtrykker enighed og bruges til fælles konstruktion af taleture. Såvel Gramkow (1996) som Rasmussen (1996) konkluderer, at nationalkulturel stil og kulturelle barrierer i kommunikationen ikke præger samtalerne. Det gør derimod ønsket om at samtalen skal lykkes. Aktørerne konstruerer deres konversation i fællesskab, og etableringen af en fælles forståelse er af største vigtighed. Gramkow mener ikke, at dette forhold nødvendigvis gør sig gældende i alle interkulturelle samtaler, men siger at samtalesituationen og den form for motivation, der præger netop denne type samtaler, kan have betydning for samarbejdet.

En anden type CA-projekter er komparative studier af samtaleorganisation i forskellige kulturer. Her er det centrale interessen for at kortlægge kulturelle mønstre i kommunikationen og finde ud af hvilke forskelle og ligheder, der er tale om i samtaler på modersmålet i forskellige kulturelle kontekster. Steensig (under udarbejdelse, se også 1996) undersøger de konversationelle fænomener turopbygning, projicering og responsivitet. Han viser, at der er tale om grundlæggende fællesprincip- 
per for turopbygning på dansk og tyrkisk. På begge sprog er opbygningen af mulige turenheder trinvis og åben, dvs. at der fra et givet tidspunkt $\mathrm{i}$ turopbygningsprocessen projiceres forskellige mulige videre forløb, som deltagerne delvist kan forudsige, reagere på og påvirke. Midlerne til turopbygning og -projicering er grammatiske, prosodiske, pragmatiske og sekventielle. Vægtningen af de forskellige midler er dog ikke den samme i de to sprog. Med hensyn til deltagernes 'responsivitet' er der iøjnefaldende forskelle i de danske og de tyrkiske data. I de danske data er der en hyppig brug af markører af fortsættelses-accept (continuers), mens modtagerne i de tyrkiske samtaler bidrager mindre eksplicit til den interaktionelle konstruktion. Med hensyn til hvad disse resultater kan bruges til i den interkulturelle forskning mener Steensig, at det er muligt at lave en hypotese om forskelle i tendens til at respondere i bestemte sekventielt definerede situationer: tyrkerne viser mindre tendens til at udtrykke enighed ved vurderinger end danskerne, eller lidt mere firkantet sagt: tyrkerne er mindre responsive end danskerne. I min Ph.d.-afhandling ser jeg først og fremmest på turn-taking og struktur i lange taleenheder kaldet diskursenheder i mexicanske og danske forhandlinger. Jeg viser, hvilke metoder deltagerne i de to materialer tager i anvendelse, når de vil skaffe sig talerum for et længere indlæg i samtalen. Det er i høj grad tale om samme måder at signalere denne argumentationsaktivitet på. Det gøres ved at anvende bestemte elementer først i taleturen, fx. en Preface ${ }^{1}$, en metalingvisktisk rammekonstruktion $^{2}$, en uenighed-enighed-struktur ${ }^{3}$, eller ved at anvende "mira" (se) i de mexicanske diskursenheder eller "altså" i de danske. Disse tur-indledende elementer projicerer taleformatet og sætter den almindelige turn-taking-adfærd, se Sacks, Schegloff \& Jefferson (1974), ud af kraft, indtil afslutningen af den lange taletur markeres. En vigtig forskel på det danske og det mexicanske materiale forekommer i organisationen af præsekvenser, idet der efter de mexicanske Prefaces ikke optræder

1 En Preface er et foreløbigt element, der projicerer en konversationel aktivitet. Prefaces som "Can I ask you a question?" og "I wanna tell you something" (Schegloff, 1980) projicerer hhv. en spørgen og en fortællen. Prefaces består af metalingvistiske formuleringer, der optræder som selvstændige syntaktiske enheder og udgør selvstændige elementer i taleturen.

2 Metalingvistiske rammekonstruktioner består af hovedsætninger, der optræder som indledende "ramme" i en diskursenhed. I modsætning til Prefaces kan de ikke "stå alene"; de er afhængige hovedsætninger, der er integreret i taleturens positionselement.

3 Kaldes i den konversationsanalytiske terminologi for Preference. 
respons (hverken verbal eller non-verbal) fra modtageren, mens dette systematisk er tilfældet i de danske forhandlinger. Der er ligeledes tale om væsentlige forskelle med hensyn til diskursenhedernes struktur, idet der er en tendens til, at denne lange argumenterende taleenhed er bygget op af forskellige komponenter i de to materialer. Denne orientering mod en bestemt struktur i de lange indlæg fungerer som endnu et projiceringsmiddel for aktiviteten, og den fremmer en klar signalering af afslutning.

Udover at disse forskellige projekter deler metode og fokuserer på kulturproblemstillinger, er det også et fælles anliggende, at vi er meget forsigtige med at generalisere vores resultater. Det er en konsekvens af opfattelsen af, at samtaler indeholder et dynamisk element, og er situationsbundne. Men samtidig går vi ud fra at sociale individer har en kompetence og orienterer sig mod normative strukturer, og når man har behandlet et materiale, hvor de undersøgte fænomener optræder systematisk, synes det alligevel rimeligt at generalisere i et vist omfang. De fleste undlader at eksplicitere præcist, hvilken gruppe de studerede fænomener formodes at gælde for, man undlader at afgrænse, hvem gruppen af "sociale individer" er, men taler snarere om i hvilke typer aktiviteter de analyserede fænomener har gyldighed. Men mens Jefferson, Schegloff og andre fokuserer på organisation af aktiviteter uden at inddrage en kulturproblemstilling, synes det oplagt for os, der arbejder med kulturanalytiske projekter, at forholde os til, hvilke grupper vores resultater vedrører. Er det fx. nationalkulturelle forskelle på samtaleorganisation, vi kan observere, eller er der tale om metoder, der er knyttet til en særlig gruppe i samfundet? Og hvilken rolle spiller den undersøgte form for aktivitet? Eksempelvis ønsker jeg i min afhandling, med forbehold for materialets repræsentativitet, at generalisere resultaterne til at gælde for den undersøgte socio-kulturelle gruppe, når de udfører forhandlinger. Det ville ligge en konversationsanalytiker fjernt at generalisere til nationalkulturelle kategorier, og i forbindelse med Mexico ville det være særlig problematisk, på grund af landets kulturelle mangfoldighed og sociale ulighed. Det ville være problematiske at tage samtalemønster, som gør sig gældende i en særlig social og kulturel gruppes særlige aktivitet som udtryk for en generel form for kommunikativ adfærd. 


\section{Hvordan relaterer CA sig til andre kulturanalytiske metoder?}

\subsection{Den funktionalistiske værdiorienterede tilgang}

Inden for antropologien var forskningen i 1950'erne og -60'erne præget af funktionalistisk, værdiorienteret tænkning 4 , som har haft stor indflydelse på måden at forstå og analysere kultur på inden for humaniora, samfundsfag og erhvervsøkonomi (Søderberg 1996).

Inden for det funktionalistiske paradigme betragtes kultur som en integreret enhed, og man baserer sig på det klassiske antropologiske kulturbegreb. Det går ud på, at kultur er noget, som medlemmer af et samfund deler, det er et fællesskab af forestillinger, værdier og betydninger. Dette fællesskab overføres fra generation til generation som en form for kulturel programmering, der sætter betydning i system og bestemmer personers adfærd.

Liep \& Olwig (1994) siger om den funktionalistiske tradition:

“..kultur - altså forestillingerne, værdierne og betydningerne - blev forstået som en overleveret, fælles og integreret helhed, et system, som alle samfundets medlemmer var socialiseret som bærere af. Ligesom sproget blev kulturen set som et fælles symbolsystem, der gav bærerne en model af verden, og en model for hvordan man skulle opføre sig i den".

Kultur bliver i denne tilgang, ifølge Hastrup (1989) sammenlignet med en "tekst", som det er etnografens opgave at læse og fortolke, som en empirisk kategori, et form og substanssystem, som kan afgrænses objektivt i tid og rum. Ifølge Søderberg (1996) betragtes kultur som et ret statisk og homogent fænomen, som kulturforskeren kan undersøge ved at observere, spørge individer om deres holdninger og værdier, systematisere data og definere, hvori de særlige kulturtræk består.

Ved at analysere kulturens fremtrædelsesformer, dens "tekst" og konstruere modeller af den kan analytikeren afdække kulturens underliggende struktursystem, den kulturelle "grammatik" som styrer samfundsmedlemmernes kulturelle forestillinger og ytringer, men som mange i denne tradition antager, at medlemmerne ikke er bevidste om; deraf også at en af de meget anvendte lærebøger i interkulturel kommu-

4 Begreberne "funktionalisme" og "værditilgang" anvendes synonymt (se også Søderberg, 1996). 
nikation bærer titlen "Kulturgrammatik"; det drejer sig om Herlitz (1991).

Det er endvidere kendetegnende for den funktionalistiske kulturanalyse, at kulturer anses som væsentligt forskellige, fordi der er store forskelle i de holdninger og værdier, der ligger bag folks adfærd.

Kulturundersøgelser inden for det funktionalistiske paradigme, som dækker store dele af feltet interkulturel kommunikation, opererer med kulturer som nationalkulturer. Opfattelsen af, at der er tale om nationalkultur er dog ikke som sådan opstået inden for antropologien; den har forbindelse tilbage til forrige århundredes udvikling af ideen om "nationen", altså staten som et folkefællesskab forenet af samme sprog og kultur, skriver Liep \& Olwig (1994).

Navnlig ideen om den kulturelle programmering af individerne, og dermed muligheden for at forudsige hvordan personer vil reagere, var noget der vakte interesse i erhvervsøkonomiske kredse, hvor det er vigtigt at kunne forudsige folks adfærd. Disse ideer er bærende i fx. den hollandske ingeniør og antropolog Hofstedes og den amerikanske antropolog Edward T. Halls teorier, der er nogle af de mest anvendte til kulturanalyse og interkulturel kommunikation.

Hofstede $(1980,1991)$ tager udgangspunkt i den funktionalistiske værditilgang. Han foretager unders $\varnothing$ gelser af arbejdsrelaterede værdier i 40 lande, i afdelinger af IBM, og udleder af besvarelserne 4 universelle dimensioner til kulturanalyse. Dimensionerne er

"Power distance" (magtdistance), der angiver i hvilken grad informanterne accepterer, at magt er ulige fordelt; "Uncertainty avoidance" (usikkerhedsundvigelse), der angiver, hvorvidt man føler sig truet af det ukendte; "Individualism" (individualisme), der angiver, hvorvidt de adspurgte føler sig ansvarlige overfor sig selv og sine nærmeste; "Masculinity" (maskulinitet), der angiver, informanternes præference for materielle eller humane værdier.

Det viste sig sidenhen, at de såkaldte universelle dimensioner ikke kunne appliceres på dele af det asiatiske område, hvor det var helt andre forhold, der prægede samfundet. Derfor indgår der en 5. dimension i Hofstede (1991), som foreslås anvendt til analyse af asiatiske lande.

Hall \& Hall (1990) udleder på baggrund af egne observationer og interviews, ligeledes nogle universelle dimensioner til kulturanalyse, først og fremmest "High context/ low context" (kulturer med mange 
fælles regler og forventninger i forhold til kulturer med færre fælles regler og forventninger) og "Monocronic/polycronic time" (kulturer hvor man gør mange ting på én gang vs. kulturer hvor man gør én ting ad gangen) og "space" (hvor kort eller lang fysisk afstand der ideelt set skal være mellem personer i forskellige situationer). Nationalkulturer beskrives og sammenlignes ved hjælp af disse dikotomier.

Disse kulturanalytiske kategorier er blevet anvendt inden for meget forskellige områder, bl.a. til analyse af kommunikation; Gudykunst \& Nishida ( 1994), Ting-Toomy (1988) og Samovar \& Porter (1991), som er en af de mest anvendte lærebøger i interkulturel kommunikation, er eksempler på dette. Det er et gennemgående træk, at man direkte overfører dimensionerne til også at være gyldige for kommunikativ adfærd, og at man undlader at inddrage konkret datamateriale.

Da kulturforholdene determinerer kommunikationen, vil det være vanskeligt for kulturbærere fra forskellige lande at kommunikere med hinanden; der opstår forståelsesmæssige barrierer i kommunikationen. Kommunikation opfattes i denne tilgang som en lineær proces (Samovar \& Porter 1991), der består af produktion af budskab, transmission og forståelse. Afsenderen koder sin meddelelse ud fra sin "kulturgrammatik", og når modtageren skal afkode den, gøres det ud fra en anden kulturs normer, hvorved interpretation og betydning ændres i forhold til det, der var aftagerens intention. Der opstår således at kommunikationsproblem. Denne kommunikationsopfattelse står i voldsom kontrast til konversationsanalysens opfattelse af interaktion, der som nævnt går ud på, at betydning skabes i en fortsat proces mellem samtalens deltagere.

\subsection{Den fortolkende antropologi}

Inden for den nyere antropologi betragtes kultur ikke længere som form- og substanssystemer. Kultur opfattes ikke som en empirisk, men som en analytisk kategori (Hastrup, 1988a og 89). Man sætter fokus på analytikerens rolle i kulturanalysen, og mener at kultur er etnografens konstruktion, idet han/hun er forfatter til en sandsynliggørende fortælling om det fremmede. Kultur opfattes samtidig som et relationelt begreb, eftersom en kultur konstrueres i sammenligning med andre kulturer. En kultur er en komparativ størrelse, der kun kan materialisere sig i forhold til og i kontrast til en anden kultur. Etnografens kultur gennemtrænger den "anden" kultur, således at den fremmede kultur kom- 
mer til at repræsentere det, vedkommendes egen kultur ikke er. Vi ser "os selv" i forhold til "de andre".

Den antropologiske metode bygger ifølge Geertz (1973) og Hastrup (1988a, 1989) dels på den erfaring, man kommer i besiddelse af via feltarbejdet, hvor man i længere tid lever sammen med den befolkningsgruppe, man studerer, dels på fortolkningen af disse erfaringer. Disse elementer i den etnografiske analyse kan ikke holdes distinkte; de inddrages løbende i den analytiske proces. Hastrup (1989: 137) siger: "Det er i det konstante krydsklip mellem empiri og teori, eller mellem opdagelse og definition, at den almindelige kulturvidenskabelige kreativitet ligger". Det er denne vekselvirkning mellem empiri og fortolkning, der i Geertz's (1973) terminologi muliggør ændringen fra en "thin description" til "thick description".

Det er etnografens opgave at skabe sammenhæng, konstruere en læsning af et kaos af erfaringer, observationer og fx. datamateriale som interviews. Ligesom i den funktionalistiske tilgang konstruerer analytikeren en sammenhæng, et betydningssystem, men mens det forklarende værdisystem i den funktionalistiske tilgang (fx. Hofstede og Hall \& Hall) tillægges universel gyldighed, og der ikke fokuseres på analytikerens prægning af resultaterne, er den fortolkende antropologi så kritisk overfor de briller, analytikeren ser kulturen igennem, at dette forhold gøres til en metodologisk komponent.

Den fortolkende antropologi relaterer dog ikke kun konstruktionsaspektet til analytikerens interpretation, men også til kulturens medlemmer. Man interesserer sig for, hvordan aktørerne konstruerer deres sociale praksisser.

Geertz søger deltagerperspektivet i sin kulturanalyse og interesserer sig i et vist omfang for, hvordan sociale handlinger konstrueres, for han mener at det er gennem forskellige typer adfærd (sociale handlinger), at kulturen tager form (Geertz 1973:17).

Hastrup (1989) inddrager også den situationelle, den lokale produktion af kultur, som en dynamisk faktor i kulturanalysen:

"Mennesker sætter gennem konkrete handlinger hele tiden deres kultur på spil. Enhver reproduktion er potentielt en transformation. Man er ikke alene et "produkt" af sin kultur, men også hele tiden medforfatter på virkeligheden".

(Hastrup 1989: 137) 
Individer og deres handlinger er altså defineret af den sociale kontekst, men de bidrager samtidig selv til at definere konteksten.

Dette fokus på sociale handlinger og på menneskers konstruktionspotentiale betyder, at kultur ikke blot bestemmer adfærd, men at adfærd også påvirker og udvikler kulturen. Dette synspunkt står i kontrast til værditilgangens determinisme og statiske kulturbeskrivelser.

På ét punkt er Hastrups og Geertz's kulturopfattelser dog ret forskellige. Geertz mener, med udgangspunkt i sin semiotiske analyse, at sociale handlinger og deres betydning må skilles ad. Han operer med et socialt niveau, hvor konkrete former for social interaktion udspiller sig, og ser kulturen som det betydningssystem, som mennesker interpreterer deres erfaringer med, og som også tildels styrer deres handlinger. ${ }^{5}$

Hastrup (1989) mener derimod, at kultur både er tekst og kontekst. Det er både de stumper, etnografen skærer ud af verdens mangfoldighed på et eller andet valgt abstraktionsniveau, og den ramme vedkommende giver dem for at forstå deres betydning. Kultur er en helhed af materialitet og betydning, af tanke og handling. Materialitet og handling kan ifølge Hastrup ikke adskilles.

Den tolkende antropologis interesse for kommunikative forhold centrerer sig om at beskrive den fremmede kulturs symbolsystemer. I overensstemmelse med Saussures tanker om tegnets to komponenter forstås disse systemer som symboler eller realiseringer, mens konceptuelle strukturer giver disse former mening, en mening der har generel gyldighed inden for kulturen, og som ikke er situationsbunden. Geertz (1973), der analyserer balinesiske titler og slægtskabsbetegnelser, er et eksempel på dette.

5 "One of the more useful ways - but far from the only one - of distinguishing between culture and social systems is to see the former as an ordered system of meaning and of symbols, in terms of which social interaction takes place; and to see the latter as the pattern of social inteaction itself. On the one level there is the framework of beliefs, expressive symbols, and values in terms of which individuals define their world, express their feelings, and make their judgements; on the other level there is the ongoing process of interactive behavior, whose persistent form we call social structure. Culture is the fabric of meaning in terms of which human beings interpret their experience and guide their action; social structure is the form that action takes, the actually existing network of social relations." (Geertz, 1973: 144-145). 


\subsection{CA i forhold til den funktionalistiske kulturanalyse og den fortolkende antropologi}

Som det er fremgået er de tre tilgange til kulturanalyse meget forskellige. Den funktionalistiske tilgang med sin deduktive metode, hvor kulturanalytiske kategorier på makroniveau appliceres på konkrete former for adfærd, står i kraftig kontrast til konversationsanalysens induktive metode, der tager sit udgangspunkt i empirien, i konkrete interaktionssituationer. Den fortolkende antropologi deler interessen for deltagerperspektivet med konversationsanalysen, selvom man arbejder med meget forskellige analytiske metoder. I sin måde at adskille sociale handlinger fra kulturel betydning, og forklare sociale handlinger via et betydningssystem sådan som Geertz gør, er der dog metodologiske fællestræk med den værdiorienterede tilgang.

Jeg vil i det følgende opsummere funktionalismens, den fortolkende antropologis og den etnometodologiske konversationsanalyses kulturforståelse og vigtigste kulturanalytiske antagelser. Jeg vil tage udgangspunkt i nedenstående model, der sammenligner de tre tilgange med hensyn til kulturdefinition, forbindelsen kultur-adfærd, kommunikationsopfattelse, opfattelse af analytikerens rolle og datamateriale/ metode, og kort kommentere de enkelte aspekter. 


\section{Funktionalisme}

Kulturdefinition

Kultur-adfærd

Kommunikationsopfattelse

Analytikerens opgave
Nationale fællesskaber med fælles værdier

Kultur er en empirisk kategori.

Kultur determinerer adfærd. tageren interpreterer.
Kortlægge adfærd og forklare den.
Fortolkende antropologi

Lokalt gældende Sociale handlinger betydningssystem. i konkrete situatio-

Kultur er en analytisk kategori.

Gensidigt determinerende. ner.

\section{CA}

Sociale/kulturelle handlinger er synlige.

Gensidigt determinerende: Aktørerne orienterersig mod normer.

Samtale er interaktiv. Betydning skabes af aktørerne i fællesskab.
Forfatte en sandsynliggørende fortælling.

Kvalitative undersøgelser.
Beskrive social og kulturel organisation.

Kvalitative (og kvantitative) undersøgelser.

\section{Kulturdefinition}

Mens funktionalismen sætter kulturer lig nationale fællesskaber, som individerne er socialiseret ind i, mener den fortolkende antropologi (Geertz, 1973), at kultur er et kompliceret betydningssystem, der ikke kan generaliseres til andre kulturer. Konversationsanalysen, der er en sociologisk metode i modsætning til de andre, beskæftiger sig med sociale handlinger. Når metoden anvendes på kulturproblemstillinger, kan man ligesom Moerman (1988) ikke skelne mellem sociale og kulturelle metoder. Konversationsanalytikerne fokuserer ikke kun på kulturelle forskelle i deres data, men på metoder til social og kulturel 
konstruktion. Nogle metoder vil være fælles, andre vil være forskellige, og endelig vil der være tale om forskelle med hensyn til hvor hyppigt de samme konversationelle fænomener optræder. Når man generaliserer, gøres det først og fremmest inden for den pågældende aktivitetskategori og under hensyntagen til særlige situationelle forhold.

Mens funktionalismen opfatter kultur som en empirisk kategori, der kan beskrives ret objektivt, opfatter den fortolkende antropologi kultur som en analytisk kategori, der opstår som kontrast til andre kulturer; kulturbeskrivelsen fremstår som analytikerens konstruktion på baggrund af medlemmernes fortolkning af deres egen virkelighed. CA ligger her tættest på funktionalismens antagelser: den relevante kulturelle kontekst viser samtaleparterne hinanden. Analytikerens fortolkning anses for minimal.

\section{$\underline{\text { Kultur-adfærd }}$}

I den funktionalistiske tilgang anses en kulturs værdi- og betydningssystem for afgrænsede størrelser og man mener, at kultur er determinerende for adfærd, da deltagerne er kulturelt programmerede. I den fortolkende antropologi er kultur og adfærd gensidigt determinerende, således at det kulturelle betydningssystem tildels styrer medlemmernes handlinger, men samtidig sker der en situationel konstruktion af kultur/kulturel betydning. I CA-tilgangen forstås forbindelsen kulturadfærd som en refleksiv proces: aktørerne orienterer sig mod nogle sociale og kulturelle normer, når de samtaler, men samtidig skabes social og kulturel kontekst $\mathrm{i}$ interaktionen.

\section{Kommunikationsopfattelse}

Funktionalismen opererer med den lineære kommunikationsmodel, hvor transmissionen foregår som en énvejsbevægelse fra afsender til modtager, og eventuelle problemer forbindes med perceptionen. Den fortolkende antropologi har navnlig interesseret sig for symbolsystemer og deres kulturelle betydning. Disse symboler analyseres ikke i interaktion, men som selvstændige størrelser, sådan som der meget eksplicit gøres opmærksom på i Moerman (1988), og de gøres til genstand for fortolkning i den antropologiske metode. I den konversationsanalytiske tradition opfattes produktion af betydning som en interaktiv proces mellem samtalens parter, og samtalen som en fælles konstruktion. Betydningen er under konstant udvikling i samtalen, og parterne viser hinanden, hvordan de forstår den. 


\section{Analytikerens opgave}

I den funktionalistiske tilgang er analytikerens opgave at kortlægge adfærd og forklare den ved hjælp af det underliggende værdi- og betydningssystem. I den fortolkende antropologi består opgaven i at skrive en sandsynliggørende fortælling om de fremmede kulturer, skabe sammenhæng i et virvar af forskellige indtryk og informationer. I CA er analytikerens opgave at beskrive social og kulturel organisation, som den anvendes af deltagerne i samtaler.

\section{Datamateriale og metode}

Funktionalismen arbejder ofte med kvantitative undersøgelser, fx. spørgeskemaundersøgelser, sådan som Hofstede gør. Men andre som fx. Hall bygger sine dimensioner til kulturanalyse på observationer og interviews, og materialets art, omfang osv. redegøres der ikke nærmere for. Den fortolkende antropologi baserer sig på kvalitative data: observationer, personlig indlevelse og interviews. CA baserer sig på båndoptagelser, helst videooptagelser af interaktion og transskriptioner af samtaler. Det er en overvejende kvalitativ metode, men i de fleste CA-arbejder kommer det kvantitative aspekt ind, idet hyppigheden af de studerede fænomener bestemmes på større samtalemængder.

\section{Konklusion}

Konkluderende kan man sige om den etnometodologiske konversationsanalyse, at den kan bidrage til kulturanalysen på væsentlige områder: med sin analytiske metode til behandling af datamateriale, med sin behandling af kontekst, med sin interaktive kommunikationsopfattelse, og med sin socialkonstruktivistiske, refleksive forståelse af sociale og kulturelle forhold.

Konversationsanalysen udgør et formelt værktøj til analyse af kontekstbaseret samtaleorganisation, med hvilket deltagernes kommunikative metoder og mikrosociologiske organisation kan beskrives. Interessen for empirien, og etableringen af en formel beskrivelse før man inddrager interpretationer af makrosociologisk karakter, kan tjene som dokumentation for eller sandsynliggørelse af, at en bestemt kulturel kontekst er relevant. Ofte vil den kulturelle kontekst dog vise sig som en særlig form for samtaleorganisation i bestemte aktiviteter, og ikke som strukturer på nationalkulturelt niveau. Deltagerne i interaktionen besidder i den tradition ikke identiteter med generel gyldighed; den 
relevante kontekst gфres relevant af deltagerne i samtalen. Det er ikke nødvendigvis sådan, at lægen viser sin professionelle identitet eller at mexicanerens nationale tilhørsforhold er relevant i en bestemt samtalesituation.

Konversationsanalysens interaktive kommunikationsopfattelse er grundlæggende for en forståelse af den fælles konstruktion af betydning, der foregår i samtaler. Netop fordi man ikke opfatter kommunikationen som en énvejsproces fra afsender til modtager, der afsluttes med modtagerens mere eller mindre fejlagtige interpretation $\mathrm{i}$ forhold til afsenderens intention, men som en fortsat konstruktion af betydning mellem deltagerne, udgør afvigelser fra velkendte kommunikative metoder ikke nødvendigvis et problem eller en barriere. Opstår der uoverensstemmelse i forståelsen mellem parterne, kan en række reparerende foranstaltninger til afklaring og gensidig tilpasning i kommunikationen tages i anvendelse.

Endelig kan konversationsanalysen bidrage med en dynamisk kulturopfattelse, via sin refleksive forståelse af forholdet mellem sociale/ kulturelle normer og interaktionssituationer. Samtidig med at deltagerne orienterer sig mod velkendte strukturer, determinerer disse ikke interaktionen. Da virkeligheden konstrueres i situationen, kan man ikke med sikkerhed forudsige, hvordan en samtale vil forløbe. Den situationelle virkelighedskonstruktion $\emptyset$ ver i al sin mangfoldighed indflydelse på de gældende sociale og kulturelle normer, og kulturen må derfor anses for at være i konstant udvikling overalt hvor der handles.

\section{Referencer}

Atkinson, J.M. \& Drew, P (1979). Order in Court: the Organisation of Verbal Interaction in Judicial Settings. London: Macmillan.

Bilmes, Jack. (1992). Dividing the rice: A microanalysis of the mediator's role in a Northeren Thai negotiation. Language in Society 21: 569-602.

Bilmes, Jack (1994). Ethnomethodology, culture and implicature: toward an empirical pragmatics. Ikke publiceret artikel fra Ph.d.-seminar: Pragmatics, Culture and Interaction. AUC.

Condon, John C. (1984). With respect to the Japanese: A guide for Americans. Yarmouth, ME: Intercultural Press.

Dahl, Øyvind (1995). Some trends in the development of the field of intercultural communication in the United States. I Ø. Dahl (red) Intercultural Communication and Contact. Stavanger: Misjonshøgskolens Forlag. 
Day, Dennis \& Firth, Alan (1996). Where's the Culture? On Conceptions of 'Culture' in Cross-cultural Communication Research. Artikel præsenteret på 3rd annual symposium in the Nordic Network for Intercultural Communication on Intercultural Communication and National Identity. Aalborg Universitet.

Doi, Takeo (1973). The anatomy of dependency. New York: Harper and Row.

Garfinkel, Harold \& Sacks, Harvey (1970). On formal Structures of Practical Actions. I J.C. McKinney (ed.) Theoretical Sociology: 337-366. Genoptrykt i Harold Garfinkel (ed.) (1986). Ethnomethodological Studies of Work: 160-194. London: Routledge \& Kegan Paul.

Geertz, Clifford (1973). The Interpretation of Cultures. Selected Essays. NY: Basic Books.

Gramkow, Karsten (1996). International Communication in Lingua Franca English. Artikel præsenteret ved 5th International Pragmatics Conference. Mexico City, juli 1996.

Gramkow, Karsten (Ph.d.-afhandling under udarbejdelse). The joint production of conversation in encounters between non-native speakers: An investigation into turn-sharing and collaborative overlap in lingua franca English. Institut for Sprog og Internationale Kulturstudier, Aalborg Universitet.

Gudykunst, William B: \& Nishida, Tsukasa (1994). Japanese/North American differences. Communicating effectively in multicultural contexts, no. 1. London: SAGE.

Hall, Edward T. (1959). The Silent Language. Garden City, NY: Anchor Press/ Doubleday.

Hall, Edward T. \& Hall, Mildred R. (1990). Understanding Cultural Differences. New York: Intercultural Press.

Hastrup, Kirsten (1988a). Etnografiens udfordring. Fortællingen om det anderledes. I Hastrup, Kirsten \& Ramløv, Kirsten (red.) Feltarbejde. Oplevelse og metode i etnografien: 11-21. København: Akademisk Forlag.

Hastrup, Kirsten (1988b). Sandhed og synlighed. Autenticitetsproblemer i antropologien. I Hastrup, Kirsten \& Ramløv, Kirsten (red.) Feltarbejde. Oplevelse og metode i etnografien: 217-227. København: Akademisk Forlag.

Hastrup, Kirsten (1989). Kultur som analytisk begreb. I Hastrup \& Ramløv (red.) Kulturanalyse. Fortolkningens forl $\phi b$ i antropologien: 11-25. København: Akademisk forlag.

Heritage, John (1984). Garfinkel and Ethnomethodology. Cambridge, UK: Polity Press.

Herlitz, Gillis (1991). Kulturgrammatik - kunsten at møde andre kulturer. København: Munksgaard.

Hilbert, Richard A. (1992). The Classical Roots of Ethnomethodology. the University of North Carolina Press.

Hofstede, Geert (1980). Culture's Consequences. Internationel Differences in Workrelated Values. Beverly Hills: Sage. 
Hofstede, Geert (1991). Cultures and Organizations - software of the mind. London: McGraw-Hill.

Kjærbeck, Susanne (1996a) (Ph.d-afhandling, OU, under udgivelse). En undersøgelse af diskursorganisation i danske og mexicanske forhandlinger: Turn-taking og struktur i Diskursenheder. Copenhagen Working Papers in LSP. Handelshøjskolen i København.

Kjærbeck, Susanne (1996b) (under udgivelse). The Organization of Discourse Units in Mexican and Danish Business Negotiations. Paper præsenteret ved 5th International Pragmatics Conference, Mexico City. Journal of Pragmatics 29 (1998).

Kjærbeck, Susanne (1997). Taleturen i kulturen - den etnometodologiske konversationsanalyse som kulturanalytisk bidrag. I K. Hjort (red) Diskurs - analyser af tekst og kontekst. København: Samfundslitteratur.

Lebra, Sugiyama, Takie (1976). Japanese patterns of behavior. University of Hawaii Press.

Liep, John \& Olwig, Karen Fog (1994). Komplekse liv. Kulturel Mangfoldighed $i$ Danmark. København: Akademisk Forlag.

Mandelbaum, Jenny (1990/91). Beyond Mundane Reasoning: Conversation Analysis and Context. Research on Language and Social Interaction 24: 333-351.

McIlvenny, Paul (1996). Crossing Cultures, Doing Genders; Reproducing Borders,: The Performative Instabilities of "Intercultural" Interactions. Artikel præsenteret på 3rd annual symposium in the Nordic Network for Intercultural Communication on Intercultural Communication and National Identity. Aalborg Universitet.

Moerman, Michael (1977). The Preference for Self-correction in a Thai Conversational Corpus. Language 53, 4:872-82.

Moerman, Michael (1988). Talking Culture. Ethnography and Conversation Analysis. Philadelphia: University of Pennsylvania Press.

Moerman, Michael (1990/91). Exploring Talk and Interaction. I Research on Language and Social Interaction 24: 173-88.Moerman, Michael (1996). The field of analyzing foreign language conversations. Journal of Pragmatics 26: 147-158.

Nomura, Naoki \& Barnlund, Dean (1983). Patterns of interpersonal criticism in Japan and the United States. International Journal of Intercultural Relations 7(1): 1-18.

Pomerantz, Anita (1990/91). Mental Concepts in the Analysis of Social Action. Research on Language and Social Interaction 24: 299-311.

Rasmussen, Gitte (1996) (Ph.D-afhandling, OU). Zur Kulturalität in interkulturellen interlingualen Gesprächen - eine Mikroanalyse deutschsprachiger Interaktionen zwischen Franzosen und Dänen und zwischen Deutschen und Dänen.

Rasmussen, Gitte (under udgivelse). Interkulturel kommunikation - begreber og metoder. RASK, internationalt tidsskrift for sprog og kommunikation. Odense Universitetsforlag.

Sacks, Harvey, Schegloff, Emanuel A. \& Jefferson, Gail (1974). A simplest systematics for the organization of turn-taking for conversation. Language 50: 696-735 (også i 
Schenkein, J. (ed.) (1978), Studies in the organization of conversation. N.Y: Academic Press).

Samovar, Larry A. \& Porter, Richard E. (1991) (6. udg.). Intercultural Communication - a reader. Belmont, CA: Wadsworth.

Schegloff, E.A. (1987). Between Macro and Micro: Contexts and Other Connections. I Alexander et al. (ed.). The Micro-Macro Link: 207-234. Berkeley: University of California Press.

Schegloff, E.A. (1991). Reflections on Talk and Social Structure. I Boden, D. \& Zimmerman, D.H. (eds.) Talk and Social Structure: Studies in Ethnomethodology and Conversation Analysis: 44-70. Cambridge, UK: Polity Press.

Schegloff, E.A. (1992a). In another context. I Duranti, A. \& Goodwin, C. (eds.). Rethinking context. Language as an interactive phenomenon. Cambridge University Press.

Schegloff, E.A. (1992b). On talk and its institutional occasions. I Drew \& Heritage (eds.). Talk at Work: 101-136. Cambridge University Press.

Silverman, David (1993). Interpreting Qualitative Data. Methods for Analysing Talk, Text and Interaction. London: SAGE.

Steensig, Jakob (1996). 'Responsivity' - an Interculturally Relevant Factor in conversations? Artikel præsenteret på 3rd annual symposium in the Nordic Network for Intercultural Communication on Intercultural Communication and National Identity. Aalborg Universitet.

Steensig, Jakob (Ph.d.-afhandling under udarbejdelse). Grammatik og interaktion $i$ dansk og tyrkisk. Bidrag til en turtagningsgrammatik for danske og tyrkiske dagligdagssamtaler ud fra en lingvistisk og konversationsanalytisk tilgang. Institut for Lingvistik, Aarhus Universitet.

Søderberg, Anne-Marie (1996). Do national cultures always make a difference? Theoretical considerations and empirical findings related to a series of case studies of foreign acquisitions of Danish companies. Artikel præsenteret på 3rd annual symposium in the Nordic Network for Intercultural Communication on Intercultural Communication and National Identity. Aalborg Universitet.

Ting-Toomy, S. (1988). Intercultural Conflict Styles. A Face-Negotiation Theory. I Kim, Y.Y. \& Gudykunst, W.B. (eds.). Theories in Intercultural Communication: 213-232. Newbury Park, CA: SAGE. 
